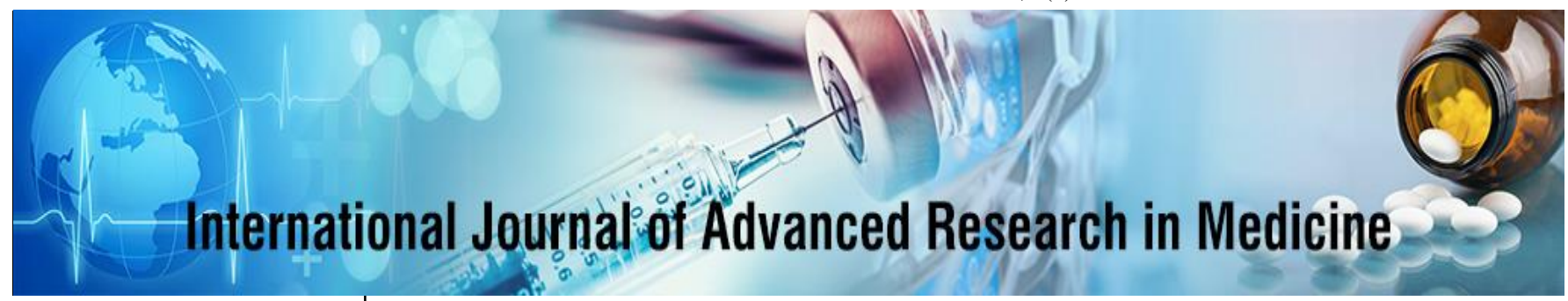

E-ISSN: 2706-9575 P-ISSN: 2706-9567 IJARM 2020; 2(2): 275-278 Received: 12-05-2020 Accepted: 16-06-2020

Dr. Suresh Patel MD Medicine, Metro Hospital and Cancer research Center Jabalpur Madhya Pradesh, India

\section{A retrospective assessment of nephrotoxicity induced by streptomycin and benefit of antioxidant vitamin $\mathrm{C}$}

\author{
Dr. Suresh Patel \\ DOI: https://doi.org/10.22271/27069567.2020.v2.i2d.133
}

\begin{abstract}
Aims: The study was aimed at exploring oxidative stress induced during kidney damage by streptomycin and benefit of antioxidant vitamin C.

Material and methods: This was a Retrospective observational and analytical study was done in the Department of Medicine, Metro Hospital and Cancer Research Centre, Jabalpur, MP from April 2018 to March 2019. Total 40, around 18 weeks old adult, male albino wistar strain rats were used with an average weight of around 170 gms. There were 4 groups, with 10 rats in each. The drug administered was as follows: Group I Control group, was given saline $0.3 \mathrm{ml}$ i.p. per day. Group II was given Vitamin C $0.2 \mathrm{mg} / \mathrm{kg} /$ day i.p. Group III was given streptomycin $100 \mathrm{mg} / \mathrm{kg} /$ day i.m. While group IV received streptomycin and vitamin $C$ with $100 \mathrm{mg} / \mathrm{kg} /$ day i.m. and $0.2 \mathrm{mg} / \mathrm{kg} / \mathrm{day}$ i.p. respectively. Blood urea and s. creatinine were measured to estimate renal damage. To measure oxidative stress Glutathione peroxidase (GPx), Glutathione reductase (GR) and Total antioxidant status (TAS) were analyzed.

Results: There was an increase of GPx by $10 \%$ in vitamin C group, while GR and TAS were increased by $5 \%$ and $29 \%$ respectively as compared to control. In streptomycin treated group all values were significantly decreased as can be seen from tables. Co administration of vitamin C significantly prevented oxidative stress and reduced formation of free radicals. There was significant rise in the level of blood Uear and S. Creatinine in streptomycin treated group. When vitamin C was co-administered changes were less evident.

Conclusion: We concluded that the antioxidant vitamin $\mathrm{C}$ has shown predictive benefit in streptomycin induced nephrotoxicity.
\end{abstract}

Keywords: Streptomycin, free radicals, glutathione peroxidase, glutathione reductase, total antioxidant status, nephron toxicity

\section{Introduction}

Streptomycin is an antibiotic used to treat a number of bacterial infections. This includes tuberculosis, Mycobacterium avium complex, endocarditis, brucellosis, Bur Kholderia infection, plague, tularemia, and rat bite fever. For active tuberculosis it is often given together with isoniazid, rifampicin, and pyrazinamide. It is given by injection into a vein or muscle. Common side effects include feeling like the world is spinning, vomiting, numbness of the face, fever, and rash. Use during pregnancy may result in permanent deafness in the developing baby. Use appears to be safe while breastfeeding. It is not recommended in people with myasthenia gravis or other neuromuscular disorders. Streptomycin is an aminoglycoside. It works by blocking the ability of $30 \mathrm{~S}$ ribosomal subunits to make proteins, which results in bacterial death ${ }^{[1]}$. The most concerning side effects, as with other aminoglycosides, are kidney toxicity and ear toxicity. Transient or permanent deafness may result. The vestibular portion of cranial nerve VIII (the Vestibulocochlear nerve) can be affected, resulting in tinnitus, vertigo, ataxia, kidney toxicity, and can potentially interfere with diagnosis of kidney malfunction ${ }^{[2]}$. Common side effects include vertigo, vomiting, numbness of the face, fever, and rash. Fever and rashes may result from persistent use. Use is not recommended during pregnancy. Congenital deafness has been reported in children whose mothers received streptomycin during pregnancy. Use appears to be okay while breastfeeding. It is not recommended in people with myasthenia gravis. Streptomycin is a protein synthesis inhibitor. It binds to the small $16 \mathrm{~S}$ rRNA of the $30 \mathrm{~S}$ subunit of the bacterial ribosome, interfering with the binding of formyl-methionylt RNA to the $30 \mathrm{~S}$ subunit ${ }^{[3]}$.
Corresponding Author: Dr. Suresh Patel MD Medicine, Metro Hospital and Cancer research Center Jabalpur Madhya Pradesh, India 
This leads to codon misreading, eventual inhibition of protein synthesis and ultimately death of microbial cells through mechanisms that are still not understood. Speculation on this mechanism indicates that the binding of the molecule to the $30 \mathrm{~S}$ subunit interferes with $50 \mathrm{~S}$ subunit association with the mRNA strand. This results in an unstable ribosomal-mRNA complex, leading to a frameshift mutation and defective protein synthesis; leading to cell death ${ }^{[4]}$. Humans have ribosomes which are structurally different from those in bacteria, so the drug does not have this effect in human cells. At low concentrations, however, streptomycin only inhibits growth of the bacteria by inducing prokaryotic ribosomes to misread mRNA ${ }^{[5]}$. Streptomycin is an antibiotic that inhibits both Grampositive and Gramnegative bacteria ${ }^{[6]}$, and is therefore a useful broadspectrum antibiotic Streptomycin was first isolated on October 19, 1943, by Albert Schatz, a PhD student in the laboratory of Selman Abraham Waksman at Rutgers University in a research project funded by Merck and Co. Waksman and his laboratory staff discovered several antibiotics, including actinomycin, clavacin, streptothricin, streptomycin, grisein, neomycin, fradicin, candicidin, and candidin. Of these, streptomycin and neomycin found extensive application in the treatment of numerous infectious diseases. Streptomycin was the first antibiotic cure for tuberculosis (TB). In 1952 Waksman was the recipient of the Nobel Prize in Physiology or Medicine in recognition "for his discovery of streptomycin, the first antibiotic active against tuberculosis". Waksman was later accused of playing down the role of Schatz who did the work under his supervision, claiming that Elizabeth Bugie had a more important role in its development ${ }^{[7]}$. Generation of free radicals and injury due to free radicals is implicated in a number of pathogenic processes including nephropathy [8-10]. So it was conceived to examine possibility of generation of free radicals and their involvement in inflicting kidney damage by widely used aminoglycoside streptomycin in experimental animal model. Further it was also planned to explore the efficacy of an antioxidant agent [11, 12] svitamin $\mathrm{C}$ to prevent and/or to reverse the structural damage in kidneys resulting due to streptomycin.

Material and Methods: This was a Retrospective observational and analytical study was done in the Department of Medicine, Bihar from April 2018 to March 2019, after taking the approval of the protocol review committee and institutional ethics committee.

\section{Methodology}

Total 40, around 18 weeks old adult, male albino wistar strain rats were used with an average weight of around 170 gms. Food and water was given as per their daily requirement. There were 4 groups, with 10 rats in each. The drug administered was as follows: Group I Control group, was given saline $0.3 \mathrm{ml}$ i.p. per day. Group II was given Vitamin C $0.2 \mathrm{mg} / \mathrm{kg} /$ day i.p. Group III was given streptomycin $100 \mathrm{mg} / \mathrm{kg} /$ day i.m. While group IV received streptomycin and vitamin C with $100 \mathrm{mg} / \mathrm{kg} /$ day i.m. and 0.2 $\mathrm{mg} / \mathrm{kg} /$ day i.p. respectively. Total duration of treatment was 30 days with single daily dose of each drug.

Sodium thiopentone $50 \mathrm{mg} / \mathrm{kg}$ i.p. was given for euthanasia, and blood was collected from heart with puncture and stored in heparinized bulbs and plain bulbs. Kidney sample was kept in $10 \%$ formalin. Blood urea and s. creatinine were measured to estimate renal damage. To measure oxidative stress Glutathione peroxidase (GPx), ${ }^{[13] \quad \text { Glutathione }}$ reductase (GR) ${ }^{[14]}$ and Total antioxidant status (TAS) ${ }^{[15]}$ were analyzed.

\section{Statistical analysis}

One way ANOVA with post hoc analysis was done. $P<0.05$ was considered statistically significant.

\section{Results}

There was an increase of GPx by $10 \%$ in vitamin C group, while GR and TAS were increased by $5 \%$ and $29 \%$ respectively as compared to control. In streptomycin treated group all values were significantly decreased as can be seen from tables. Co administration of vitamin $\mathrm{C}$ significantly prevented oxidative stress and reduced formation of free radicals. There was significant rise in the level of blood uear and s.creatinine in streptomycin treated group. When vitamin $\mathrm{C}$ was co-administered changes were less evident. Distal tubules have smaller diameter as compared to proximal tubules. There is presence of brush border in proximal tubules while distal tubules are devoid of brush border with clearer luminar surface. The proximal tubular structure shows remarkable damage with derange epithelia. Cellular necrosis is found in many proximal tubules. Prominent damage to renal brush border is seen. Distal tubule are showing less disruption. Larger proximal tubules display less damage, along with vital epithelium. In some PCT only damage to brush border is seen while integrity of brush border in other is well maintained. Preservation of normal cellular structure is evident.

Table 1: Effect of streptomycin and vitamin $C$ induced changes in blood urea, serum creatinine, glutathione peroxidase, glutathione reductase and total antioxidant status

\begin{tabular}{|c|c|c|c|c|c|c|}
\hline Group & $\begin{array}{c}\text { Drug } \\
\text { treatment }\end{array}$ & $\begin{array}{l}\text { B. urea } \\
\text { mg\% }\end{array}$ & $\begin{array}{l}\text { S. creatinine } \\
\text { mg\% }\end{array}$ & $\begin{array}{c}\text { Glutathione } \\
\text { Peroxidase U/l }\end{array}$ & $\begin{array}{c}\text { Glutathione } \\
\text { Reductase U/l }\end{array}$ & $\begin{array}{l}\text { Total Antioxidant } \\
\text { Status mmol/l }\end{array}$ \\
\hline I & Saline & $38 \pm 2.14$ & $0.58 \pm 0.11$ & $1017 \pm 47$ & $74 \pm 12.32$ & $1.31 \pm 0.03$ \\
\hline II & Vitamin $\mathrm{C}$ & $41 \pm 2.55$ & $0.62 \pm 0.11$ & $1087 \pm 78$ & $81 \pm 4.78$ & $1.59 \pm 0.05 * * *$ \\
\hline III & Streptomycin & $47 \pm 1.9 *$ & $1.30 \pm 0.24 *$ & $775 \pm 31 * * *$ aa & $49 \pm 2.6 *$ aa & $1.21 \pm 0.02 * * *$ aaa \\
\hline IV & Streptomycin + Vitamin C & $41 \pm 1.21 * b$ & $0.61 \pm 0.18 \mathrm{bb}$ & $869 \pm 42 * a$ & $66 \pm 3.2 \mathrm{~b}$ & $1.32 \pm 0.02 \mathrm{aaabbb}$ \\
\hline & $\begin{array}{c}\text { ANOVA } \\
\mathrm{F} ; \mathrm{d} \mathrm{P} \text { value }\end{array}$ & $\begin{array}{c}3.042 ; 3,33 \\
0.0487\end{array}$ & $\begin{array}{c}6.759 ; 3,33 \\
0.0017\end{array}$ & $\begin{array}{c}9.94 ; 3,33 \\
0.0002\end{array}$ & $\begin{array}{c}4.37 ; 3,33 \\
0.0155\end{array}$ & $\begin{array}{c}70.71 ; 3,33 \\
0.0001\end{array}$ \\
\hline
\end{tabular}

Values are mean \pm SEM; $* P<0.05, * * P<0.01$ and $* * * P<0.001$ when compared to group I. a $P<0.05$, aa $P<0.01$ and aaa $P<0.001$ when compared to group II. $\mathrm{b} P<0.05, \mathrm{bb} P<0.01$ and bbb $P<0.001$ when compared to group III

\section{Discussion}

Streptomycin is one of the drugs in treatment of tuberculosis, plague and other diseases due to gram negative organisms. In renal glands streptomycin gets reabsorbed and get concentrated in cells of proximal tubules. High value of trough is responsible for the renal damage. Mechanism of 
renal damage is less explored, but there is skepticism about the role of oxidative stress and free radical generation. Coadministraion of vitamin $\mathrm{C}$ can be of some benefit in preventing renal damage due to its scavenging action exerted on free radicals [16-18]. Histopathological examination revealed kidney damage produced by administration of streptomycin in present study. Renal structure was disrupted especially in proximal convoluted tubules. Marked degenerative changes were observed. In some tubular cells piknotic nuclei were found suggesting patchy necrosis. Recently involvement of free radicals is under scanner in many diseases owing to their ability of cellular disruption ${ }^{[19-21]}$. Free radicals are highly reactive due to unstable electron in their outer orbital ring, and can pause a potential threat to integrity of any cellular structure [22]. GPx and GR are powerful antioxidants and prevent formation of free radicals and thereby also prevent lipid peroxidation as well as cell damage. TAS is the value of individual's ability to fight against oxidative stress produced by free radicals. Treatment with streptomycin for 30 days there was significant reduction in the value of all the parameters of oxidative stress namely GPx, GR and TAS. Leonard et al. ${ }^{[23]}$ also observed renal damage characterized by acute tubular necrosis after using tobramycin $200 \mathrm{mg} / \mathrm{kg} /$ day. Sens et al. ${ }^{[24]}$ studied effect of increasing concentration of streptomycin on the human proximal tubular cell culture. They monitored for cell death, light and electron microscopic changes under both resting and actively dividing culture conditions. Damage to renal brush border and microvilli was evident as this one is active site for drug transport. Kavutcu et al. also found similar reduction in GPx level in guinea pig while studying effect of gentamicin ${ }^{[25]}$. Reduction in antioxidant level is totally reflected in the value of TAS. Once established the involvement of oxidative stress in renal injury due to streptomycin it was necessary to examine the role of antioxidant vitamin $\mathrm{C}$ which is natural antioxidant and free radical scavenger ${ }^{[26-28]}$. Lemon, orange, strawberries like fruits are rich in vitamin $\mathrm{C}$ having antioxidant ability. Free radicals like peroxyl and hydroxyl radicals are scavenged by vitamin $C^{[29]}$. In present study it was found that there was significant increase in GPx and GR level. Hong et al. observed protective role of vitamin $\mathrm{C}$ at $0.18 \mathrm{mg} / \mathrm{kg} / \mathrm{day}$ in nephrotoxicant injury ${ }^{[30]}$. Bradberry and Vale found similar protective role of vitamin $\mathrm{C}$ at $0.5 \mathrm{mg} / \mathrm{kg} /$ day in chromium induced renal damage ${ }^{[31]}$. In removal of free radical there is competition between vitamin C and GPx or GR enzymes. As a result use of vitamin $C$ reduces fall in the level of GPx as well as GR level and as a result overall increase in TAS value. In present study rise in TAS level in vitamin C treated group supports antioxidant ability of vitamin C. In vitro studies have shown ability to generate free radicals and induce oxidative stress with aminoglycoside antibiotics. ${ }^{[32]}$ In renal cortical mitochondria, formation of free radical like super oxide as well as hydrogen peroxide have been associated with aminoglycosides ${ }^{[33-35]}$. A notorious hydroxyl radical is formed due to interaction between super oxide anion and hydrogen peroxide which can pause a threat to mitochondrial DNA as well as matrix. Formation of free radicals can also damage other cellular organelle and cell membrane. All these can lead to leakage of protein from inside out. 18 Zima et al. compared the action of free radical with second messanger system and formation of various interleukins which can ultimately enhance proteolytic activity, damage collage and extracellular matrix in glomerular structure ${ }^{[36]}$. In present study rise in level of blood urea and s. creatinine was suggestive of renal damage due to streptomycin.

\section{Conclusion}

The present study concluded that the antioxidant vitamin $\mathrm{C}$ has shown predictive benefit in streptomycin induced nephrotoxicity in present study however more extensive studies are desirable to arrive to a definite conclusion.

\section{Reference}

1. Kirtane AJ, Leder DM, Waikar SS, Chertow GM, Ray KK, Pinto DS, et al. TIMI Study Group. J Am Coll Cardiol 2005;45(11):1781-6.

2. Streptomycin Sulfate. The American Society of HealthSystem Pharmacists. Archived from the original on December 20, 2016. Retrieved 2016.

3. Syal K, Srinivasan A, Banerjee D. Streptomycin interference in Jaffe reaction Possible false positive creatinine estimation in excessive dose exposure. Clinical Biochemistry 2013;46(1-2):177-179. doi:10.1016/j.clinbiochem.2012.10.031.PMID 23123914.

4. Sharma D, Cukras AR, Rogers EJ, Southworth DR, Green R. Mutational analysis of $\mathrm{S} 12$ protein and implications for the accuracy of decoding by the ribosome. Journal of Molecular Biology. 2007;374(4):1065-76. doi:10.1016/ j.jmb.2007.10.003. PMC 2200631. PMID 17967466.

5. Raymon Lionel P. COMLEX Level 1 Pharmacology Lecture Notes. Miami, FL: Kaplan, Inc, 2011, 181. CM4024K.

6. Voet Donald, Voet Judith G. Biochemistry (3rd ed.). John Wiley \& Sons, 1994, 1341. ISBN 978-0-47119350-0.

7. Jan-Thorsten Schantz, Kee-Woei Ng. A manual for primary human cell culture. World Scientific, 2004, 89.

8. Sahnoun Z, Jamoussi K, Zeghal KM. Free radicals and antioxidants: human physiology, pathology and therapeutic aspects. Therapie 1997;52:251-70

9. Hogg N. Free radicals in disease. Semin Reprod Endocrinol 1998;16:41-8.

10. Knight JA. Free radicals: their history and current status in aging and disease. Ann Clin Lab Sci 1998;28:331-46

11. Wayner DD, Burton GW, Ingold KU. The antioxidant efficiency of vitamin $\mathrm{C}$ is concentration-dependent. Biochem Biophys Acta 1986;884:119-23

12. Padh H. Vitamin C: newer insights into its biochemical functions. Nutr Rev 1991;49:65-70.

13. Paglia DE, Valentine WN. Studies on the quantitative and qualitative characterization of Glutathion Proxidase. J Lab Med 1987;70:158-65.

14. Goldberg DM, Spooner RJ. In: Methods of enzymatic analysis. Bergmeyer HB editor 1992;3:258-6.

15. Miller NJ, Rice-Evans C, Davies MJ, Gopinathan V, Milner A. A novel method for measuring antioxidant capacity and its application to monitoring the antioxidant status in premature neonates. Clin Sci 1993;84:407-12.

16. Walker PD, Barri Y, Shah SV. Oxidant mechanisms in gentamicin nephrotoxicity. Ren Fail 1999;21:433-42. 
17. Walker PD, Shah SV. Evidence suggesting a role for hydroxyl radical in gentamicin-induced acute renal failure in rats. J Clin Invest 1988;81:334-41.

18. Du XH, Yang CL. Mechanism of gentamicin nephrotoxicity in rats and the protective effect of zincinduced metallothionein synthesis. Nephrol Dial Transplant 1994;9:135-40.

19. Sahnoun Z, Jamoussi K, Zeghal KM. Free radicals and antioxidants: human physiology, pathology and therapeutic aspects. Therapie 1997;52:251-70.

20. Hogg N. Free radicals in disease. Semin Reprod Endocrinol 1998;16:41-8.

21. Knight JA. Free radicals: their history and current status in aging and disease. Ann Clin Lab Sci 1998;28:331-46.

22. Fujita T, Fujimoto Y. Formation and removal of active oxygen species and lipid peroxides in biological systems. Nippon Yakurigaku Zasshi 1992;99:381-9.

23. Leonard I, Zanen J, Nonclercq D, Toubeau G, HeusonStiennon JA, Beckers JF et al. Modification of immunoreactive EGF and EGF receptor after acute tubular necrosis induced by tobramycin or cisplatin. Ren Fail 1994;16(5):583-608.

24. Sens MA, Hennigar GR, Hazen-Martin DJ, Blackburn JG, Sens DA. Cultured human proximal tubule cells as a model for aminoglycoside nephrotoxicity. Ann Clin Lab Sci 1988;18(3):204-14.

25. Kavutcu M, Canbolat O, Ozturk S, Olcay E, Ulutepe S, Ekinci $\mathrm{C}$ et al. Reduced enzymatic antioxidant defense mechanism in kidney tissues from gentamicin-treated guinea pigs: effects of vitamins $\mathrm{E}$ and C. Nephron 1996;72:269-74.

26. Coudert P, Leal F, Duroux E, Rubat C, Couquelet J. Effect on free radical processes of some ascorbic acid analogues. Biol Pharm Bull. 1996;19:220-3.

27. Fujita T, Fujimoto Y. Formation and removal of active oxygen species and lipid peroxides in biological systems. Nippon Yakurigaku Zasshi 1992;99:381-9.

28. Padh H. Vitamin C: newer insights into its biochemical functions. Nutr Rev 1991;49:65-70.

29. Wayner DD, Burton GW, Ingold KU. The antioxidant efficiency of vitamin $\mathrm{C}$ is concentration-dependent. Biochim Biophys Acta 1986;884:119-23.

30. Hong SK, Anestis DK, Ball JG, Valentovic MA, Brown PI, Rankin GO. 4-amino-2, 6-dichlorophenol (ADCP) induced nephrotoxicity in the Fischer 344 rat: protection by ascorbic acid, AT-125 and aminooxacetic acid. Fundam Appl Toxicol. 1997;39:131-7.

31. Bradberry SM, Vale JA. Therapeutic review: is ascorbic acid of value in chromium poisoning and chromium dermatitis? J Toxicol Clin Toxicol 1999;37:195-200.

32. Sha SH, Schacht J. Stimulation of free radical formation by aminoglycoside antibiotics. Hear Res. 1999;128:112-8.

33. Yang CL, Du XH, Han YX. Renal cortical mitochondria are the source of oxygen free radicals enhanced by gentamicin. Ren Fail 1995;17:21-6.

34. Walker PD, Shah SV. Evidence suggesting a role for hydroxyl radical in gentamicin-induced acute renal failure in rats. J Clin Invest 1988;81:334-41.

35. Sha SH, Schacht J. Stimulation of free radical formation by aminoglycoside antibiotics. Hear Res 1999;128:112-8.
36. Zima T, Tesar V, Stipek S, Nemecek K, Platenik J. The role of oxygen radicals in the pathogenesis of glomerulonephritis. Cas Lek Cesk 1995;134:716-9. 